\title{
Pesquisa-Intervenção e a Produção de Novas Análises
}

Participatory action research and the production of new analysis

Resumo: Partindo de um histórico das pesquisas participativas nos seus diferentes momentos de constituição e propostas relativas às mudanças na produção de conhecimento, este trabalho tem como perspectiva apresentar e discutir os pressupostos teórico-metodológicos da pesquisa-intervenção. A pesquisa-intervenção vem constituindo-se em um dispositivo de transformação vinculado tanto à formação acadêmica dos psicólogos, quanto às práticas nas instituições, possibilitando novas análises construídas entre a macro e a micropolítica.

Marisa Lopes da Rocha

Profa adjunta $e$ pesquisadora em

Educação do

Departamento de Psicologia Social e Institucional do Instituto de Psicologia da UERJ. Mestre em Filosofia da Educação pelo IESAE/

FGV. Doutora em Psicologia pelo Núcleo de Estudos e Pesquisas da Subjetividade na PUC/SP.

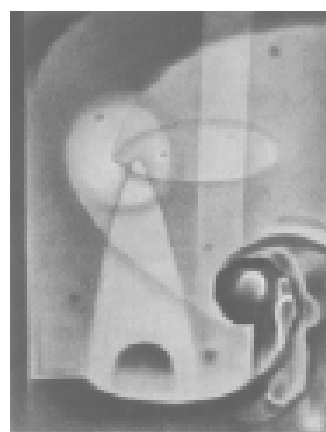

Katia Faria de Aguiar

Profa adjunta e pesquisadora do Departamento de Psicologia da UFF Mestre e Doutora em Psicologia Social na PUC/SP

Palavras-chave: pesquisa participativa, pesquisa-intervenção, Psicologia Institucional.

Abstract: On the basis of a historical review of participative research along its different moments of constitution, and assuming some proposals related to transformation in the production of knowledge, this paper aims to discuss the theoretical and methodological presumptions of intervention-research. Interventionresearch can be seen as a means of achieving transformation in what concerns academic formation of professionals in Psychology as well as the practices in institutions, offering the possibility of new analysis grounded on macro and micropolitics.

Key words: participative research, intervention-research, Institutional Psychology.

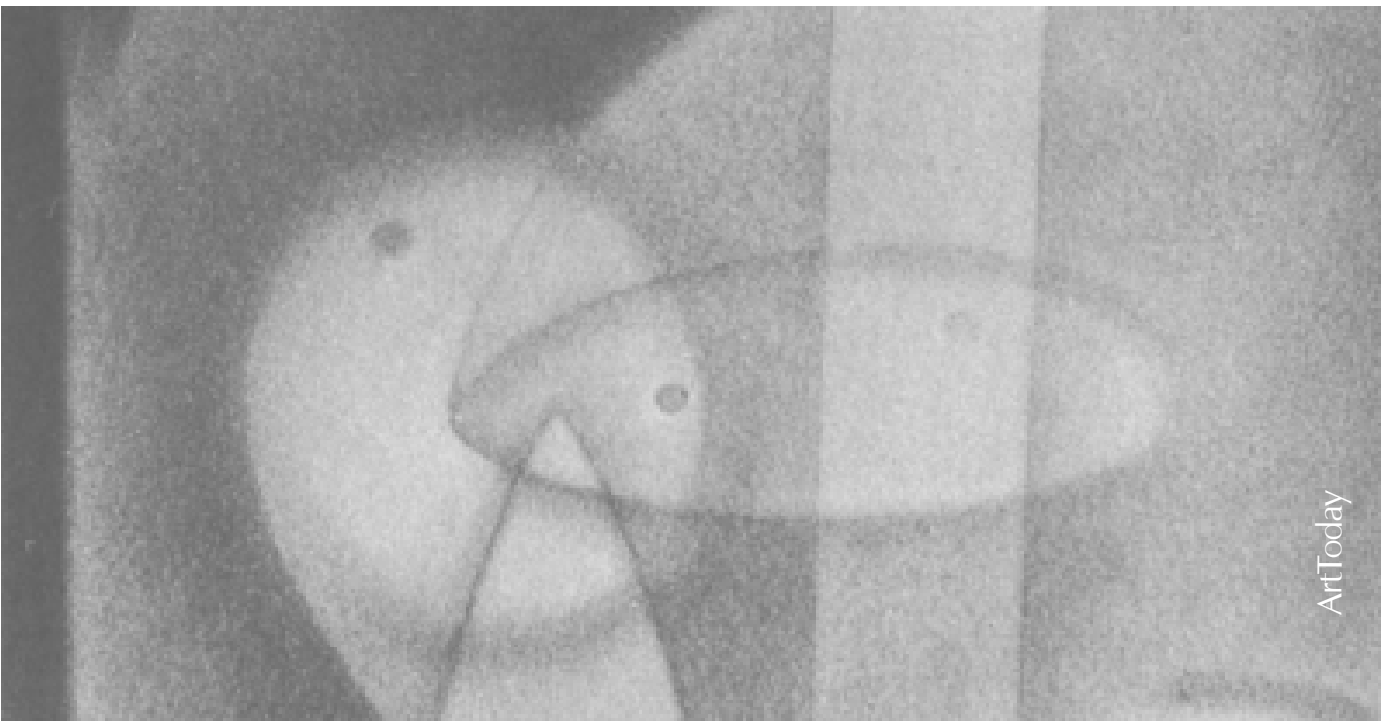

Este trabalho tem por objetivo discutir os pressupostos da pesquisa-intervenção que vêm viabilizando a construção de espaços de problematização coletiva junto às práticas de formação e potencializando a produção de um novo pensar/fazer educação. A pesquisa-intervenção em nossa experiência faculta um duplo e simultâneo projeto: por um lado, redimensiona a formação acadêmica dos profissionais de Psicologia, apontando para a perspectiva sóciohistórico-política; por outro, constrói novas bases para as ações dos psicólogos nas instituições, contribuindo para a organização de equipes que queiram assumir o desafio de colocar em análise suas implicações com as práticas produzidas, entendendo as situações cotidianas como acontecimentos sociais complexos , determinados por uma heterogeneidade de fatores $\mathrm{e}$ de relações.

\section{Pesquisas Participativas: uma História e um Outro Modo de Produção de Conhecimento}

As primeiras experiências com pesquisas de campo estão vinculadas às iniciativas lewinianas no final da década de 30 nos Estados Unidos, inaugurando uma outra possibilidade de articulação entre teoria e prática, sujeito e objeto nas investigações sociológicas, 
psicológicas, educacionais, organizacionais (Saidon, 1983, Barbier, 1985). Tal proposta se afirma, tanto no sentido de resolver questões concernentes aos problemas de ajustamento das populações marginais, trabalhar as crises nas relações de trabalho e aliviar tensões em situações problemáticas, quanto no sentido de desenvolver as ciências sociais, através de ações concretas na realidade, refletindo criticamente e avaliando seus resultados. Lewin (1969) criava a pesquisa-ação e a dinâmica de grupo, fundamentando uma psicossociologia ativa frente às questões sociais, em que a gênese social precedia a gênese teórico-metodológica. Segundo Barros (1994a), Lewin também desestabilizava o mito da objetividade na produção do conhecimento, ressaltando que a implicação do pesquisador está presente no processo da investigação e que, por estar incluído no campo, sua ação (entrevistas, questionários, dinâmicas, análises de dados e devolução das informações obtidas) modifica o objeto estudado.

Porém, se as inserções dos cientistas sociais nos grupos e organizações ganham consistência principalmente no pós-guerra, a partir das experiências lewinianas, suas ações estarão referenciadas a demandas construídas fora das práticas, uma vez que vinculadas à hierarquia reguladora das relações sociais. Assim, ganham prioridades no setor industrial questões como a formação de quadros dirigentes e o controle dos comportamentos organizacionais. Nos serviços estratégicos, as iniciativas passam a girar em torno da investigação das técnicas de guerra psicológica para enfraquecer o inimigo e, ainda, nos trabalhos sociais, a ênfase estará na integração nos conjuntos habitacionais e na delinqüência juvenil, problemáticas que, certamente, já evidenciavam alguns dos efeitos do modelo de desenvolvimento sócio-econômico no espaço urbano. Segundo Barbier (1985), enquanto Marx já havia proposto pesquisas realizadas pelos próprios operários para analisar os efeitos da exploração, Lewin procura, nos mecanismos de estimulação e competição introduzidos pela pesquisa-ação desenvolvida na Harwood Manufacturing Corporation em 1939, aumentar a produtividade das operárias.

Desse modo, embora a perspectiva da pesquisa de campo lewiniana estivesse constituindo uma nova forma de investigação e de ação sobre o campo social diversa da tradição positivista, as análises dos fatos desencadeados por suas pesquisas não fugiam do paradigma funcionalista, já que eram direcionadas à compreensão das disfunções produzidas pelos erros de estratégia do pesquisador e das crises promovidas por agentes patológicos do campo. Ainda em Barros (1994a), para Lewin, a ordem social é naturalizada e as crises e conflitos são interpretados como desordens, efeitos disfuncionais, cujas resistências à mudança são alvos de intervenção. As análises se fazem sobre o nível microorganizacional com a perspectiva de otimizar recursos e relações para um funcionamento social adequado. A pesquisa ganha uma dimensão utilitária e o pesquisador, o papel de agente facilitador do amadurecimento das relações humanas. As experiências lewinianas nos EUA se constituem em um aprimoramento do sistema capitalista, mantendo cisões como teoria/prática e sujeito/objeto, definindo uma linha de chegada a priori e modelos a serem atingidos.

Na América Latina, considerando a existência de países submetidos durante longo período a governos autoritários, a pesquisa-ação crítica, assim diferenciada das experiências reformistas desenvolvidas nos EUA, estará ligada a projetos emancipatórios e autogestionários, principalmente nos movimentos comunitários e nas iniciativas em educação popular junto a populações excluídas (Thiollent, 1987). Entendida como uma ação que visa a mudanças na realidade concreta com uma participação social efetiva, a pesquisa-ação crítica está centrada no agir, através de uma metodologia exploratória, tendo seus objetivos definidos no campo de atuação pelo pesquisador e pelos participantes. Seus resultados estão vinculados à tomada de consciência dos fatores envolvidos nas situações de vida imediata e na participação coletiva para a mudança da ordem social. A identificação de problemas e possíveis soluções e o estabelecimento de programas de ação constituem procedimentos que podem ser utilizados com a ajuda de técnicas tradicionais como as da pesquisa documental, dinâmicas de grupo, informações vivas e opinativas dos participantes (Brandão, 1987). Os dados são sempre provisórios e se aplicam a grupos de pequena e média dimensão.

Tais experiências caminham no sentido da articulação entre teoria/prática e sujeito/objeto, na medida em que o conhecimento e a ação sobre a realidade se fará na investigação das necessidades e interesses locais, na produção de formas organizativas e de uma atuação efetiva sobre essa realidade, podendo levar a transformações sociais e políticas, dando às populações excluídas uma presença ativa na História.

No Brasil, nos últimos anos da década de 60 e em quase toda a década seguinte, contexto de forte repressão política, observa-se a desestabilização e o conseqüente enfraquecimento dos movimentos populares, a clandestinidade ou mesmo a transferência de militantes e intelectuais para o exterior (Aguiar, 2003). No entanto, os que conseguiram permanecer no País e mantiveram-se na luta pelo restabelecimento de um trabalho democrático junto aos setores marginalizados da sociedade contaram com a atuação de intelectuais e de setores da Igreja vinculados ao movimento da Teologia da Libertação e das Comunidades Eclesiais de Base (Rizzini, Castro e Sartor, 1999).
1 o sentido que damos à palavra complexidade não está ligado a confuso, complicado ou ao que envolve muitos elementos ou partes intrincadas, mas o utilizado por Morin (1980), em que a complexidade éum outro modo de organização de nossas idéias, um modo capaz de religar os conhecimentos fragmentados $\mathrm{em}$ especializaçóes na era moderna. Um pensamento complexo ou uma análise da complexidade seria, então, capaz de articular. olocal, o singular (microssocial), com as representaçōes eformas instituídas em um contexto mais amplo (macrossocial), favorecendo as análises das implicações sócio-históricopoliticas pelo coletivo. A mudança das práticas teria conseqüências existenciais, éticas, solidarizando os homens, redefinindo a própria noção de cidadania, que abandona o estatuto da ordem legal para o exercício crítico da ação. 
Já no final da década de 70 se abrirá uma nova perspectiva de investigação a partir do questionamento às pesquisas tradicionais, incluindo discussões no que tange ao fracionamento da vida social, à dicotomização entre ciência e política e à conseqüente inviabilização de uma participação efetiva de grupos sujeitados nos rumos da sociedade. O pesquisador, nessa nova visão, apresenta-se como um intelectual orgânico às causas populares, e a pesquisa-ação se traduz em um método potencializador na organização de espaços de participação coletiva. Política e educação, política e organização de comunidades constituem-se em relações possíveis para transformar a realidade.

No cenário latino-americano, noções como educação e cultura popular, participação e autonomia ganham relevo e orientam as ações dos trabalhadores sociais, principalmente com experiências em escolas comunitárias e em diferentes iniciativas nos campos da saúde e da moradia. Voltadas à construção de alternativas ao sistema formal/ estatal, tais experiências acompanham mudanças em curso nos movimentos sociais e apontam para intelectuais-pesquisadores estabelecidos em universidades e organizações não-governamentais, novas formas de organização e de produção do conhecimento.

O entendimento de que as questões sociais devem ser problematizadas com os grupos e as organizações populares, a consideração da necessária contextualização das questões e ações empreendidas e a complexidade dos processos de mudança, próprios do referencial básico das pesquisas participativas, aparecem como elementos fundamentais à construção e ao exercício de uma cidadania ativa. Relativizando a idéia de "verdade", abandonam a neutralidade, a objetividade e a totalização dos saberes, pilares das ciências tradicionais. Nesse sentido, a transformação da realidade vivida não seria uma questão da correta aplicação dos conhecimentos produzidos nas hierarquias formalizadas, colocando-se como possibilidade a partir da interação entre o saber acadêmico, em seus diversos campos de conhecimento, e os saberes dos sujeitos individuais e coletivos envolvidos na pesquisa.

\section{Considerações Sobre as Possíveis Diferenças entre Pesquisa Participante/Participativa, Pesquisa-Ação e Pesquisa- Intervenção}

Como constatam Rizzini, Castro e Sartor (1999), na literatura estrangeira a principal preocupação entre os pesquisadores não está diretamente ligada à diferença entre as metodologias da pesquisa participativa (PP) e da pesquisa-ação (PA), mas entre as pesquisas participativas e não participativas. Já na literatura brasileira, as diversas tendências metodológicas que envolvem o conceito de participação apresentam maior polêmica, gerando muitas vezes dificuldades quanto à sua compreensão. Em Thiollent, por exemplo, uma clara distinção mostra-se necessária, pois a PA é uma forma de PP, mas nem todas as PP são PA:

"A PP se preocupou sobretudo com o papel do investigador dentro da situação investigada e chegou a problematizar a relação pesquisador/pesquisado no sentido de estabelecer a confiança e outras condições favoráveis a uma melhor captação de informação. No entanto, os partidários da PP não concentraram suas preocupações em torno da relação entre investigação e ação dentro da situação considerada. É justamente esse tipo de relação que é especificamente destacado em várias concepções da PA. A PA não é apenas PP, é um tipo de pesquisa centrada na questão do agir" (Thiollent, 1987: 83).

Em Oliveira e Oliveira (1985), encontramos os pressupostos das pesquisas participativas sem uma distinção entre as diferentes abordagens de trabalho em campo, as quais são afirmadas como estratégias de pesquisa que têm como proposta a participação dos grupos sociais na busca de soluções para as problemáticas vividas, envolvendo um processo de compreensão e mudança da realidade. Segundo os autores, para desenvolver uma metodologia participativa, é necessária uma mudança na postura do pesquisador e dos pesquisados, uma vez que todos são co-autores do processo de diagnóstico da situação-problema e da construção de vias que possam resolver as questões. É um processo contínuo que acontece no curso da vida cotidiana, transformando os sujeitos e demandando desdobramentos de práticas e relações entre os participantes.

Independentemente de ter ou não um tempo determinado para o seu desenvolvimento, que varia segundo os recursos materiais e humanos disponíveis, o fundamental nas pesquisas participativas é que o conhecimento produzido esteja permanentemente disponível para todos e possa servir de instrumento para ampliar a qualidade de vida da população. Podemos considerar que a pesquisa participante se constitui em uma metodologia com pressupostos gerais de pesquisa, envolvendo diferenciados modos de ações investigativas e de priorização de objetivos. A pesquisa-intervenção consiste em uma tendência das pesquisas participativas que busca investigar a vida de coletividades na sua diversidade qualitativa ${ }^{2}$, assumindo uma intervenção de caráter socioanalítico (Aguiar, 2003; Rocha, 1996, 2001). Rodrigues e Souza (1987) evidenciam que a pesquisa-intervenção representa uma crítica à política positivista de pesquisa: 
"A antiga proposta lewiniana vem sendo re-significada à luz do pensamento institucionalista: trata-se, agora, não de uma metodologia com justificativas epistemológicas, e sim de um dispositivo de intervenção no qual se afirme o ato político que toda investigação constitui. Isso porque na pesquisaintervenção acentua-se todo o tempo o vínculo entre a gênese teórica e a gênese social dos conceitos, o que é negado implícita ou explicitamente nas versões positivistas 'tecnológicas' de pesquisa" (Rodrigues e Souza, 1987: 31).

Em relação à gênese da pesquisa-intervenção e à construção da sua singular abordagem no Brasil (Saidon e Kankahagi, 1987), podemos identificar o movimento institucionalista francês, na década de 60, e o latino-americano nas décadas seguintes, como experiências em meio às quais ela se afirmará como uma prática ético-estético-política ${ }^{3}$.

O processo de formulação da pesquisa-intervenção aprofunda a ruptura com os enfoques tradicionais de pesquisa e amplia as bases teórico-metodológicas das pesquisas participativas, enquanto proposta de atuação transformadora da realidade sócio-política, já que propõe uma intervenção de ordem micropolítica na experiência social. O que se coloca em questão é a construção de uma "atitude de pesquisa" que irá radicalizar a idéia de interferência na relação sujeito/objeto pesquisado, considerando que essa interferência não se constitui em uma dificuldade própria às pesquisas sociais, em uma subjetividade a ser superada ou justificada no tratamento dos dados, configurando-se, antes, como condição ao próprio conhecimento (Santos, 1987, Stengers, 1990).

A pesquisa afirma, assim, seu caráter desarticulador das práticas e dos discursos instituídos, inclusive os produzidos como científicos, substituindo-se a fórmula "conhecer para transformar" por "transformar para conhecer" (Coimbra, 1995). Podemos, então, destacar, para a formulação da pesquisa-intervenção, referenciais importantes como uma certa concepção de sujeito e de grupo, de autonomia e práticas de liberdade e a de ação transformadora:

\section{Concepção de Sujeito e de Grupo}

O processo de consolidação do capitalismo se faz na perspectiva de um tempo espacializado, cronológico, e em sua especialização nos campos de saber e nos encargos de seus peritos especialismos/especialistas. O aparecimento de novos espaços e a modificação de outros já existentes seguem uma racionalidade marcada pelo investimento no individual e sua inscrição em uma totalidade, através da funcionalidade e do equilíbrio. Será nesse contexto, o de uma "tecnologia de enclausuramento", que serão fundadas tanto as imagens de equivalência sujeito-indivíduo quanto o sentido de unidade fechada presente nos conceitos de sujeito e de grupo (Barros, 1994b).

A equivalência sujeito-indivíduo servirá para o congelamento das possibilidades de análise dos processos de subjetivação, plurais e heterogêneos, sustentando a concepção de sujeito enquanto consciência unitária presente nas teorias construídas ao longo da era moderna. Além disso, o pressuposto da interioridade, pretendendo garantias frente à ameaça desestabilizadora da multiplicidade de uma realidade que the é exterior, irá aprofundar a cisão homem X mundo.

Muitas das teorias críticas produzidas nessa época permanecem presas a tal perspectiva quando, por exemplo, estabelecem a noção de homem como consciência sujeitada, resultado da dominação (homem alienado - inconsciente das determinaçõ̃es sociais externas, preso às ideologias), ou como consciência liberta, representando a resistência à dominação (homem crítico - lúcido em relação às determinações ideológicas de uma sociedade dividida em classes). Ao pressuposto implicado nessa visão de homem colocado frente à realidade, somamse as disjunções sujeito/objeto e teoria/prática, uma vez que a emancipação está no descobrimento de fatores pré-determinados.

A ruptura com essa concepção investe na criação de novos referenciais que coloquem em questão as formas hegemônicas circunscritas. Sendo a subjetividade efeito de múltiplas determinações em tensão, a consciência seria sempre parcial, existindo em permanente conflito no processo de entendimento da vida e, portanto, sem a possibilidade de um estado pleno de lucidez.

A crítica feita às teorias estruturalistas dirige-se ao sujeito humanista naturalizado e essencializado, portador de uma subjetividade nuclear que pode ser reprimida pela sociedade ou, de outro modo, atualizar-se de forma livre.

Silva (1993), discutindo os pressupostos cientificistas no que tange à falsa ou à verdadeira consciência, estabelece que a ciência não desvela a ideologia, uma vez que a própria postura científica é parte do problema, e não a solução. A ideologia, segundo o autor, é uma visão invertida de uma realidade material considerada fixa e o significado nunca é fixo, tendo como referente o "real". O significado é produzido nas práticas, em tensão permanente com as representações hegemônicas.

Também em Foucault (1999) percebemos que o conhecimento não se circunscreve à dualidade falso $\mathrm{x}$ verdadeiro, pois é acontecimento e tem caráter
3 Na perspectiva de Guattari
(1992), a Ética está referida
ao exercicio do pensamento que
avalia situaçóes e
acontecimentos como
potencializadores ou não de
vida; a Estética traz a
dimensäo de criação,
articulando os diferentes
campos do pensamento, da
ação e da sensibilidade; a
politica implica a
responsabilização frente aos
efeitos produzidos, ou seja,
sobre os sentidos que vão
ganhando forma através das
açöes individuais e coletivas. 
perspectivo, polêmico. O conhecimento, sempre parcial, é efeito de lutas a partir de uma certa relação estratégica, onde o homem está situado. Nesse sentido, o conhecimento é tanto generalizante quanto singular, uma vez que prioriza regularidades, ignorando as diferenças, mas é também fruto de engendramento, de estabelecimento de relações entre os objetos. Na visão foucaultiana, as condições econômicas de existência não representam barreira para o sujeito do conhecimento, evidenciando, antes, a materialidade através da qual este se constitui e, conseqüentemente, as relações de verdade. Ao invés de conhecimento verdadeiro, Foucault $(1981,1999)$ afirma serem produzidos regimes de verdade. O ser da ciência é equilíbrio e estabilidade porque o pressuposto é a objetividade, a representação estática, eterna, sujeito espacializado e não contextualizado no tempo.

Na sociedade contemporânea, cuja complexidade, temporalidade acelerada e heterogeneidade são fatores preponderantes, uma prática emancipatória não pode se sustentar no conceito de ideologia que se vincula à visão de uma sociedade bipolarizada, cujo movimento se faz pela contradição entre as classes nos seus valores, interesses e necessidades. O que está em questão não é deixar de considerar a possibilidade de um recorte do social referido às classes, mas perceber que outras clivagens podem estar em jogo, pois as formas de inserção na vida social são múltiplas e muitas vezes outros vetores movem o cotidiano do coletivo com mais intensidade (Guattari e Rolnik, 1986). Nesse sentido, não se trata de substituir a análise de classes por qualquer outra estabelecida a priori, nem por análises que cotejem os movimentos sociais e os diferentes grupos como grupos-em-si ou grupos-para-si, mas considerar os grupos como dispositivos de afirmação de outros modos de subjetivação, realidades abordadas micro e macropoliticamente.

\section{Autonomia e Práticas de Liberdade}

Os questionamentos às formulações que se enraízam na época moderna evidenciam uma racionalidade científica que possibilita apenas uma forma de conhecimento verdadeiro, ligando o seu exercício à quantificação e à redução da complexidade (Santos, 1987). Em sua extensão enquanto modelo global, a racionalidade científica terá de forjar defesas contra os conhecimentos não científicos e eliminar os acidentes e incidentes de seu percurso. Volta-se para as regularidades e extrai delas leis deterministas e universais, aqui referidas como macroteorizações.

As macroteorizações apresentam uma visão teleológica da História, ou seja, constituem-se como superteorias que definem uma finalidade para a história humana, um destino a ser alcançado no futuro. Nessa perspectiva, o encargo social dos intelectuais e das vanguardas seria o de possibilitar, através de métodos e de técnicas adequadas, o descortinamento da realidade objetiva, o acesso à verdade.

A postura crítica desenvolvida a partir das referências macrossociais, que buscam relacionar a razão, a funcionalidade e os resultados de uma determinada forma de organização ao contexto sócio-político e econômico, pode significar um primeiro passo facilitador para as análises das atividades realizadas no cotidiano. As contribuições de Marx e Engels (1986) apontam para a história como produto da ação dos homens e, desse modo, põem em discussão a perspectiva da transformação a partir dos movimentos sociais. Porém, se tal pressuposto desautoriza qualquer forma de naturalização e, portanto, de um suposto evolucionismo social, alguns modos de apropriação do legado marxista acabam por reintroduzir o determinismo causalista nas orientações tanto das análises quanto das intervenções.

São especialmente os estruturalismos que se incumbirão de organizar formulações que terminam por esvaziar a potência, vislumbrada por Marx, das experiências sociais, fazendo-as sucumbir às ultimas instâncias do econômico. No entanto, os questionamentos não se limitam apenas a esse eixo (econômico) de determinação, que condiciona o processo histórico ao desenvolvimento das forças produtivas. A polêmica estaria vinculada, antes, à idéia de causalidade e à ênfase em um futuro préconcebido e inevitável, quando o projeto se afirma como universal.

A consideração da produção da vida articulada às múltiplas interações sociais pode colocar em cheque a separação infra/superestrutura, sua relação linear, bem como seus efeitos e, ao mesmo tempo, instalar um relativismo que, embora inclua o contexto, mantém a lógica que acolhe os eventos nos termos de causa e de efeito. Embora incluindo "o social" e sua "complexidade", ainda assim o determinismo se apresenta na busca de uma teoria que possa estruturar as leis da História, ordenando acontecimentos e hierarquizando saberes e fazeres. Essa armadilha que nos é colocada por nossas implicações com um modo de existência em construção desde a modernidade pode ser observada em abordagens historicistas e sua concepção de consciência que, uma vez desalienada, conduziria a sociedade aos rumos esperados da História.

Desse modo, podemos dizer que conceitos como os de autonomia, transformação e liberdade, fundamentais nas chamadas teorizações marxistas, precisam ser redimensionados, transformando-se em um projeto que vai ganhando consistência de formas diferenciadas nas práticas coletivas: 
"A autonomia considerada como um estado a ser alcançado através de programas determinados de ação está referida à conquista de um reino futuro onde habita a liberdade. A liberdade está sempre situada fora das circunstâncias. Desse modo, a transformação passa a ser previsível no percurso estruturado como condição a priori. No entanto, a autonomia não é uma condição que, uma vez conquistada, nos leve ao estado de equilíbrio e bemestar permanente. Se a entendermos como função de autonomia, como afirmam F. Guattari \& S. Rolnik (1986), ela é exercício, movimento, práticas de transformação, estando referida ao presente, à realidade, às circunstâncias nas quais produzimos 0 cotidiano" (Aguiar e Rocha, 1997:100).

A luta pela autonomia, enquanto tomada de consciência, cede lugar à afirmação do poder das experiências, através das quais os agentes sociais se reconhecem e são reconhecidos nos tempos e espaços diferenciados que os compõem. Isso não significa deixar de colocar em análise os condicionantes político-sociais atravessados nas ações cotidianas. Segundo Silva (1993), o movimento da Pedagogia Crítica "moderna" tinha como desafio as práticas de conscientização que, na atualidade, frente ao descentramento da noção de sujeito, perdem sentido. As múltiplas determinações das posições de sujeito descaracterizam um estado privilegiado de consciência para o qual se pudesse levar o outro a ser conscientizado.

"Faz mais sentido falar num confronto de diferentes subjetividades, o que concederia uma importância maior à construção de espaços públicos de discussão e debate onde essas diferentes subjetividades tivessem a oportunidade de se defrontarem. Isso aponta para um outro importante conceito que afasta as análises pós-modernas das modernas: o conceito de 'diferença'"' (Silva, 1993: 130).

A racionalidade moderna, através da universalidade, das categorizações dicotômicas, ocupou o centro das preocupações, descaracterizando a subjetividade na sua diferença. Assim, enquanto a análise moderna tem como foco a desigualdade social, homogeneizando grupos e sujeitos, na perspectiva contemporânea a ênfase recai sobre as diferenças entre grupos e nos grupos (Rocha, 1996, Silva, 2001).

A dialética repressão x libertação supõe uma perspectiva identitária da subjetividade. Não encontramos uma realidade fora das condições concretas dos sujeitos, os discursos não são falsos ou verdadeiros, não representam a realidade, mas constituem-na. O poder, na dimensão foucaultiana, circula e não está nas mãos de uma determinada classe social, nem nas dos intelectuais. Nesse sentido, não há um lugar isento, neutro, de onde se possa falar a verdade. Não havendo um lugar privilegiado, o que seria dos agentes de mudança? (Foucault, 1981).

O cotidiano entra em cena, como espaço/tempo privilegiado ao exercício de articulação das análises micro e macropolíticas. Facultar formas singulares de participação em que se estabeleçam o confronto de subjetividades, a intensificação das relações de poder e a abertura de espaços polêmicos para o exercício da cidadania torna-se hoje imperativo ante os caminhos de libertação já circunscritos nas metanarrativas (Aguiar, 2003, Rocha, Gomes e Lima, 2003).

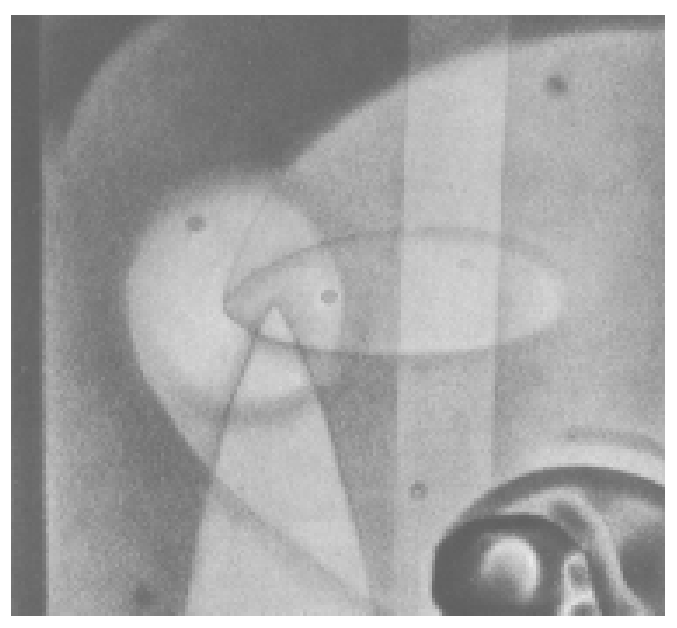

\section{"A autonomia considerada como um estado a ser alcançado atrovés de programas determinados de ação está referida à conquista de um reino futuro onde habita a liberdade. A liberdade está sempre situada fora das circunstâncias."}

Aguiar e Rocha

Não se trata de exaltação de um hedonismo de momento, mas da produção de utopias ativas, onde a constituição da autonomia se dá pela sempre limitada mas infinita questão relativa à potencialidade da vida. Se as crenças e valores socioculturais estabelecem o que pode ser, o pensar favorece o exercício ético do que deve ser e fazer frente às circunstâncias. Isso exige mudanças na ordem da existência nos seus múltiplos devires que estão além dos condicionantes culturais. Se acolhemos a máxima de que é nas condições políticas que se produzem sujeitos, domínios de saber e relações com a verdade, pensar o poder como produção de subjetividade é descentrar o poder de um sujeito verdadeiro para colocar em análise os processos de sua constituição enquanto tal. A quebra da equivalência sujeito-indivíduo, pela introdução do tempo, implica novos referenciais de análise que podem ser vistos como outra forma de pensar o poder da ação humana (Deleuze, 1988).

\section{Ação Transformadora}

A filosofia da representação, que sustenta a cultura ocidental cristã e sua racionalidade, favoreceu a absorção do múltiplo no uno, da diferença na identidade e do acaso na necessidade. No plano das representações, o que se afirma são universais onde a realidade será rebatida e codificada, sendo os

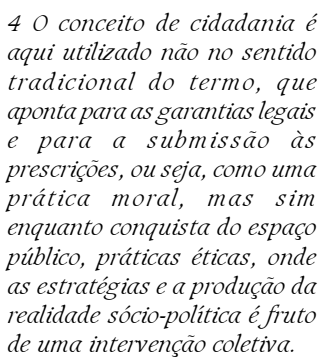

4 O conceito de cidadania é aqui utilizado não no sentido tradicional do termo, que aponta para as garantias legais e para a submissão às prescrições, ou seja, como uma prática moral, mas sim enquanto conquista do espaço público, práticas éticas, onde as estratégias e a produção da realidade sócio-politica é fruto de uma intervenção coletiva. 
acontecimentos analisados como parte de um todo previamente organizado.

Os sujeitos da lei são particularidades de uma ordem geral. A lei só determina a semelhança e a equivalência aos seus próprios termos. No entanto, os homens não são do domínio da semelhança ou da equivalência, são únicos, singulares, ou seja, insubstituíveis. A questão macro está na ordem das categorizações, da constância dos modelos e da repetição de formas já consolidadas, e não de singularização, multiplicidades e diversidades (Rocha, 1996).

A filosofia da imanência proposta por Deleuze e Guattari (1980) reconduz a unicidade e a harmonia, vinculadas aos sistemas organicamente estruturados, à pluralidade, à complexidade das forças produtoras da existência. A realidade criada na perspectiva da imanência recusa um ponto de partida, um sujeito ou uma idéia deflagradores dos acontecimentos. $\mathrm{O}$ que se produz é resultado do encontro de múltiplas dimensões ou de linhas de força entrelaçadas, sem que nenhuma tenha o papel de unidade transcendente. Nas discussões de Rolnik, apreendemos que o que existe é uma guerra de vários graus de potência e não uma luta binária entre a vida e a morte.

Diante das categorias universais, das metanarrativas, dos dualismos, da compreensão da sociedade como uma estrutura que tende ao equilíbrio e do homem como uma unidade racional controladora do mundo, a adoção de uma abordagem micropolítica trará desafios teórico-metodológicos para uma ação transformadora nos diferentes domínios da vida social.

Um primeiro desafio encontra-se na própria concepção de realidade que adotamos em nossa vida cotidiana, considerada como o conjunto de tudo aquilo a que se pode ter acesso, que se dá à observação como matéria concreta. Nessa perspectiva, para pensar as modificações da realidade, o apoio está nas possibilidades que se encontram reguladas e limitadas por leis naturais, por princípios não contraditórios, ou seja, o possível que permeia a realidade concreta e que é nascedouro de suas mudanças já estaria inscrito na ordem do existente, enquanto potencialidade ainda ocultada.

Nesse caminho, no qual acessamos as previsões e projetos de futuro, a transformação habita uma região de criatividade limitada pelo cotidiano, sendo uma possibilidade, desde que estejam dadas as condições ou os meios para a realização de um potencial já circunscrito. não o do concreto e da presença. Será com a noção de virtualidade que fará a passagem de um possível entendido enquanto material disponível à criação ou à tomada de decisões para um possível enquanto engendramento. Desse modo, na realização de um ser na dimensão da atualidade, algo continua, permanece em vias de se atualizar.

A transformação do existente não se limita à criação de condições ou meios adequados à realização de um potencial, mas refere-se a uma micropolítica que implica o intensivo, o plano dos processos de constituição de realidades, que abre o atual à pluralidade das formas de existência e qualifica a transformação enquanto criação de possíveis.

Na realidade criada na perspectiva da imanência, a dimensão micropolítica ganha importância e revela ser mais que uma dimensão na escala espacial (a do lugar) ou que uma temporalidade (a do cotidiano), abrindo a História à experiência imprevisível que se espreita no cotidiano. Isso porque a noção de movimento que ganha consistência entre a macro e a micropolítica não se faz pela negação, ou seja, pela busca de unidade/síntese como na dialética hegeliana, mas pela positividade vinculada à vontade de potência, constituída nas experiências que criam sentidos na história dos homens.

Em Nietzsche, a filosofia da vontade estabelece que toda força está em uma relação essencial com outra força, mas o ser da força é plural e não teria sentido pensar a força no singular.

"O conceito de força é, portanto, em Nietzsche, o de uma força que se relaciona com uma outra força. Sob este aspecto, a força é denominada uma vontade. A vontade (vontade de poder) é o elemento diferencial da força. Daí resulta uma nova concepção de filosofia da vontade, pois a vontade não se exerce misteriosamente sobre músculos ou sobre nervos, menos ainda sobre uma matéria em geral, ela se exerce sobre uma outra vontade" (Deleuze, 1976: 5).

"Em Nietzsche, a relação essencial de uma força com a outra nunca é concebida como um elemento negativo na essência. Em sua relação com uma outra, a força que se faz obedecer não nega a outra ou aquilo que ela não é, ela afirma sua própria diferença e se regozija com essa diferença. O negativo não está presente na essência como aquilo de que a força tira sua atividade, pelo contrário, ele resulta dessa atividade, da existência de uma força ativa e da afirmação de sua diferença" (Deleuze, 1976: 7).

Através do conceito de genealogia, Nietzsche abre um outro tempo na história da Filosofia, uma vez que escava no passado e no presente dos acontecimentos não a evolução dos fatos 
dominantes, mas os saberes menores, as forças que atuaram na sua gênese. Genealogia, então, vinculase a uma prática de desconstrução das categorias identitárias de toda a lógica constituída a partir da filosofia de Platão. O fato social se cria no enfrentamento de múltiplas forças presentes, e a configuração que se estabelece é resultante da dominância de determinadas forças sobre outras. Na filosofia nietzscheana, as transformações não são alavancadas por evolução e retificação, mas pelo diferencial de forças que intensificam a potência.

Desse modo, na perspectiva genealógica, é a diferença entre as forças que faculta a afirmação de um fenômeno instável como unidade de um momento que tenta se impor como verdade universal. No desenrolar de um movimento, nosso pensamento e nossas ações não têm início em uma contraposição, mas emergem de um conjunto de forças entre as quais existem oposições. Um movimento não surge necessariamente da crítica de um outro, o que não impede que possamos compará-los nas suas incompatibilidades.

Assim, das visões totalizadoras e das utopias passamos às ações que remetem às estratégias de análise das formas constituídas, evidenciando seu caráter fluido, polêmico, que flexibilizam divisões tradicionais, cujas práticas sociais, as experiências, são pontos de criação de sentido e não reflexo de uma realidade que está em outro lugar. Não é mais possível investir na busca do fundamento último das coisas e dos acontecimentos, na medida em que são constituídos por forças e tensões historicamente situadas e, portanto, parciais, mutáveis e dependentes das existências e dos grupos singulares, das práticas locais.

Patto (1993), para quem os dispositivos de funcionamento da vida contemporânea aceleram a perpetuação das estruturas e princípios instituídos, afirma que, na vida cotidiana, a redução a uma unidade imediata entre a ação e o pensamento tem feito com que, cada vez mais, o útil seja tomado como verdadeiro. Essa tendência econômica leva o funcionamento social à exata medida de sua continuação. Segundo a autora, as mudanças passam pela subjetividade, pela ação ativa dos atores que se constitui em um processo lento e celular, incompatível com as políticas de produtividade implementadas na atualidade.

\section{A Pesquisa-Intervenção como Dispositivo de transformação}

Na pesquisa-intervenção, não visamos à mudança imediata da ação instituída, pois a mudança é conseqüência da produção de uma outra relação entre teoria e prática, assim como entre sujeito e objeto. No âmbito da Sociologia, a questão se vincula à afirmação de uma micropolítica do cotidiano construindo uma trajetória concreta dos movimentos; no da Psicologia, envolve a recusa da individualização e da psicologização dos conflitos.

A corrente da Análise Institucional Socioanalítica, desenvolvida a partir das décadas de 60/70 na França (Lourau, Lapassade, Hess) e que ganha adeptos na América Latina na década de 80 (Rodrigues, Baremblitt, Barros), possibilitará a formulação da pesquisa-intervenção com a perspectiva de interrogar os múltiplos sentidos cristalizados nas instituições (Rodrigues e Souza, 1987, Saidon e Kamkhagi, 1987, Rodrigues, Leitão e Barros, 1992, Aguiar, 2003).

Como prática desnaturalizadora, o que inclui a própria instituição da análise e da pesquisa, as estratégias de intervenção terão como alvo a rede de poder e o jogo de interesses que se fazem presentes no campo da investigação, colocando em análise os efeitos das práticas no cotidiano institucional, desconstruindo territórios e facultando a criação de novas práticas.

Procedemos, desse modo, à crítica ao estatuto da Verdade, interpelando o poder das teorias, das organizações e das formas constituídas no que tange ao conhecimento e às relações sócio-institucionais, frente à realidade complexa e diferenciada.

Para tal fim, propomos metodologias coletivas, favorecendo as discussões e a produção cooperativa com a perspectiva de fragilização das hierarquias burocráticas e das divisões em especialidades que fragmentam o cotidiano e isolam os profissionais. A pesquisa-intervenção, por sua ação crítica e implicativa, amplia as condições de um trabalho compartilhado.

Entre os aspectos centrais que vêm norteando o desenvolvimento da pesquisa-intervenção, destacamos os seguintes: mudança de parâmetros de investigação no que tange à neutralidade e à objetividade do pesquisador, acentuando-se o vínculo entre gênese teórica e social, assim como a produção concomitante do sujeito e do objeto, questionamento dos especialismos instituídos, ampliando as análises do nível psicológico ao microssocial - deslocamento estratégico do lugar que historicamente foi destinado ao psicólogo, ênfase na análise da implicação, acentuando-se que, para além dos vínculos afetivos, profissionais ou políticos, a análise se realiza com as instituições que atravessam o processo de formação.

A intervenção está associada à construção e/ou utilização de analisadores, conceito-ferramenta formulado no percurso do institucionalismo francês, que funcionam como catalizadores de sentido, desnaturalizando o existente e suas condições e realizando a análise. 
O conceito de instituição também é modificado, não se identificando com o de estabelecimento, ganhando um sentido dinâmico, uma vez que remete a um processo de produção constante de novos modos de existência, de configuração das práticas sociais (Rodrigues, 1993, Barros, 1994a), do mesmo modo que o conceito de implicação trabalhado pelos analistas institucionais não é uma questão de vontade, de decisão consciente de ligar-se a um processo de trabalho. Ele inclui uma análise do sistema de lugares ocupados ou que se busca ocupar ou ainda do que Ihe é designado, pelo coletivo, a ocupar e os riscos decorrentes dos caminhos em construção. A análise das implicações com as instituições em jogo nas situações afirma também a recusa da neutralidade do analista/pesquisador, procurando romper com as barreiras entre sujeito que conhece e objeto a ser conhecido. A intervenção evidencia que pesquisador/ pesquisado, ou seja, sujeito/objeto fazem parte do mesmo processo.

"Na pesquisa-intervenção, a relação pesquisador/ objeto pesquisado é dinâmica e determinará os próprios caminhos da pesquisa, sendo uma produção do grupo envolvido. Pesquisa é, assim, ação, construção, transformação coletiva, análise das forças sócio-históricas e políticas que atuam nas situações e das próprias implicações, inclusive dos referenciais de análise. É um modo de intervenção, na medida em que recorta o cotidiano em suas tarefas, em sua funcionalidade, em sua pragmática - variáveis imprescindíveis à manutenção do campo de trabalho que se configura como eficiente e produtivo no paradigma do mundo moderno" (Aguiar e Rocha, 1997:97).
É nesse sentido que a intervenção se articula à pesquisa para produzir uma outra relação entre instituição da formação/aplicação de conhecimentos, teoria/prática, sujeito/objeto, recusando-se a psicologizar conflitos. Conflitos e tensões são as possibilidades de mudança, pois evidenciam que algo não se ajusta, está fora da ordem, transborda os modelos. Diante disso, ou ocupamos o lugar de especialistas, indagando sobre as doenças do indivíduo, ou o de sócio-analistas, indagando sobre a ordem da formação que exclui os sujeitos.

Grande parte das questões que bloqueiam a processualidade das práticas de formação nas quais nos inserimos estão presentes nas instituições universitárias, entre as quais a atualização de modelos universais, a naturalização da realidade social, o especialismo cientificista, traduzidos em um conjunto de técnicas a serem aplicadas. A pesquisa-intervenção vem viabilizando trabalhos de campo que colocam em análise as instituições que determinam a realidade sócio-política e os suportes teórico-técnicos, construídos no território educacional. Não há, portanto, o que ser revelado, descoberto ou interpretado, mas criado. Com efeito, por intermédio de uma abordagem micropolítica das produções coletivas, constatamos que a realidade social resiste aos quadros formulados a priori, às categorias gerais bem delimitadas, aos modelos circunscritos que não conseguem mais explicar as condições da mulher, da família, da infância, dos excluídos, instaurando-se o desafio de uma teorização permanente.

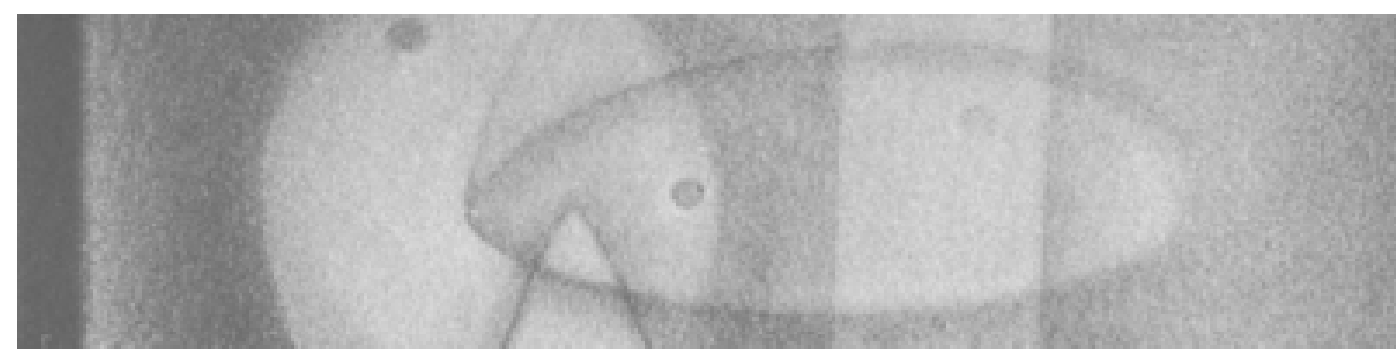


AGUIAR, K. F. e ROCHA, M. L. Práticas Universitárias e a Formação Sócio-política. Anuário do Laboratório de Subjetividade e Política, no 3/4,1997, pp. 87-102.

Ligações Perigosas e Alianças Insurgentes. Subjetividades e Movimentos Urbanos. Tese de doutorado, Pontifícia Universidade Católica de São Paulo, São Paulo, 2003.

BARBIER, R. A Pesquisa-Ação na Instituição Educativa. Rio de Janeiro: Zahar, 1985.

BARROS, R. D. B. Grupos: a Afirmação de um Simulacro. Tese de doutorado, Pontifícia Universidade Católica de São Paulo, São Paulo, 1994a

. Grupos e Produção. Saúde e Loucura - Grupos e Coletivos, no 4, 1994b pp. 145-154.

BRANDÃO, C. R. (org.) Repensando a Pesquisa Participante. $3^{\underline{a}}$ ed. São Paulo: Brasiliense, 1987.

COIMBRA, C.M. B. Os Caminhos de Lapassade e da Análise Institucional: uma Empresa Possível. Revista do Departamento de Psicologia da UFF, vol 7, no 1, 1995, pp. 52-80.

COSTA, M. V. (org.) Caminhos investigativos. Novos Olhares na Pesquisa em Educação. Porto Alegre: Mediação, 1996.

Caminhos Investigativos II. Outros Modos de Pensare Fazer Pesquisa em Educação. Rio de Janeiro: DP\&a , 2002.

DELEUZE, G. Nietzsche e a Filosofia. Rio de Janeiro: Rio, 1976.

\& Guattari, F. Mille Plateaux. Capitalisme et Schizophrénie. Paris: Minuit, 1980.

. Foucault. São Paulo: Brasiliense, 1988.

FOUCAULT, M. Microfísica do Poder. 2ed. Rio de Janeiro: Graal, 1981. $\overline{\mathrm{Nau}, 1999}$

A Verdade e as Formas Jurídicas. 2ed. Rio de Janeiro:

GUATTARI, F. Revolução Molecular. Pulsações Políticas do Desejo. 2ed. São Paulo: Brasiliense, 1985.

GUATTARI, F. e ROLNIK, S. Micropolítica. Cartografias do Desejo. Petrópolis: Vozes, 1986.

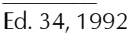

Caosmose. Um Novo Paradigma Estético. Rio de Janeiro:

HELLER, A. O Cotidiano e a História. 4o ed. Rio de Janeiro: Paz e Terra, 1970.

LEFEBVRE, H. A Vida Cotidiana no Mundo Moderno. São Paulo: Ática, 1991.

LÉVY, A. Ciências Clínicas e Organizações Sociais. Sentido e Crise do Sentido. Belo Horizonte: Autêntica, 2001.

LÉVY, A., NICOLAI, A., ENRIQUEZ, E. e DUBOST, J. (orgs). Psicossociologia. Análise Social e Intervenção. Belo Horizonte: Autêntica, 2001.

LEWIN, K. Dinámica de la Personalidad. Madrid: Morata, 1969.

LOURAU, R. Análise Institucional e Práticas de Pesquisa. In H. B. C. Rodrigues (Org.), René Lourau na UERJ. Rio de Janeiro: UERJ, 1993, pp. 7-114.
MARX, K. e ENGELS, F. A ldeologia Alemã (Feuerbach). 5ed. São Paulo: Hucitec, 1986.

MORIN, E. La Méthode. Paris: Seuil, 1980.

OLIVEIRA, M. D. e OLIVEIRA, R. D. Pesquisa Social e Ação Educativa: Conhecendo a Realidade Para Poder Transformá-la. In C. R.

BRANDÃO (org.), Pesquisa Participante. São Paulo: Brasiliense, 1985, pp. 83-95.

PATTO, M. H. S. A Produção do Fracasso Escolar. São Paulo: Queiroz, 1993.

RIZZINI, I., CASTRO, M. R. e SARTOR, C. D. Pesquisando... Guia de Metodologias da Pesquisa Para Programas Sociais. Rio de Janeiro: Universidade Santa Úrsula, 1999.

ROCHA, M.L. Do Tédio à Cronogênese: uma Abordagem Éticoestético-política da Prática Escolar. Tese de doutorado, Pontifícia Universidade Católica de São Paulo, São Paulo, 1996.

. Formação e Prática Docente: Implicações com a PesquisaIntervenção. Em I.M. MACIEL (org.), Psicologia e Educação: Novos Caminhos Para a Formação Rio de Janeiro: Ciência Moderna, 2001, pp. 175-191.

ROCHA, M.L., GOMES, L.G.W. e LIMA, I.C. Gestão do Trabalho e os Desafios da Saúde na Educação. In A.M.B. BOCK (org.) Psicologia e Compromisso Social. São Paulo: Cortez, 2003, pp. 129-141.

RODRIGUES, H. B. C. e SOUZA, V. L. B. A Análise Institucional e a Profissionalização do Psicólogo. In V. R. Kamkhagi e O. Saidon (orgs). Análise Institucional no Brasil. Rio de Janeiro: Espaço e Tempo, 1987, pp. 27- 46 .

RODRIGUES, H. B. C., LEITÃO, M. B. S. e BARROS, R. D. B. (orgs) Grupos e Instituições em Análise. Rio de Janeiro: Rosa dos Tempos, 1992.

As Subjetividades em Revolta. Institucionalismo Francês e Novas Análises. Dissertação de mestrado, Universidade do Estado do Rio de Janeiro, Rio de Janeiro, 1993.

SAIDON, O. \& KAMKHAGI, V. R. (org) Análise Institucional no Brasil. Rio de Janeiro, Rosa dos Tempos, 1987.

SANTOS, B.S. Um Discurso Sobre as Ciências. Porto: Afrontamento, 1987.

SILVA, T. T. Sociologia da Educação e Pedagogia Crítica em Tempos pós-Modernos. In ___ (org), Teoria Educacional crítica em tempos pós-modernos. Porto Alegre: Artes Médicas, 1993, pp. 122-140.

Nunca Fomos Humanos. Nos Rastros do Sujeito. Belo Horizonte: Autêntica, 2001.

STENGERS, I Quem Tem Medo da Ciência? São Paulo, Siciliano, 1990.

THIOLLENT, M. (1987). Notas Para o Debate Sobre Pesquisa-Ação. In C. R. Brandão (Org.), Repensando a Pesquisa Participante, 3 a ed. São Paulo: Brasiliense, 1987, pp. 82-103.

\section{Referências}

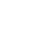

